\title{
Research on the Geniusloci in Landscape Design of University Campus
}

\author{
Qian Lin * \\ School of Logistics \\ Wuhan Technology and Business University \\ Wuhan, China
}

\author{
Haiwen Wang \\ School of Art and Design \\ Wuhan Technology and Business University \\ Wuhan, China.
}

\begin{abstract}
Chinese university is an important base for training Chinese high-level talents, Its Campus Landscape Design must have the function of cultivating excellent personality and noble spirit of Chinese university students since campus is not only a place to provide student knowledge and skills, but also an important place for training students' quality. According to the people-oriented point of view, the needs of historical heritage and the aesthetic principles of landscape design, this paper analyzes the factors of natural environment, cultural background and landscape construction to demonstrate the genius loci issue of campus landscape. Innovation of this paper is that in order to get the landscape design color, design style and material choice of thinking, it summaries the former analysis and demonstration of the campus landscape color, lighting, modeling design characteristic. This paper is hoped that this method can make the campus landscape not only achieve a certain sense of artistic beauty, but also have a rich spiritual level, so as to integrally enhance the spiritual education function of the campus, and bring more inspiration for the campus landscape design ideas.
\end{abstract}

Keywords - geniusloci; landscape; design; concept; key point of design; method

\section{INTRODUCTION}

Since humankind entered the 21st century, society, economy, culture, science and technology have entered a period of rapid development. People put forward higher requirements for material and spiritual life. At this stage, the era of too much simplistic landscape planning in Chinese universities has declared an end. People oriented landscape design with scientific and artistic feature has become the pursuit of modern people. People's expectation of campus landscape design and architectural decoration has exceeded the level of its material carrier, and hope that the campus landscape can carry more cultural connotations and social and cultural psychology. Therefore, we must thoroughly explore the concept of place design in campus landscape design, and find out the methods and measures in line with this concept.

\section{THE CONCEPT OF PLACE CONTAINED IN CAMPUS LANDSCAPE DESIGN}

\section{A. The people-oriented design concept}

The basic purpose of people's decorative design of buildings or environments is to make users feel safer and more comfortable. Therefore, we have to follow this principle when decorating and designing for the building or environment. This means that the designer must not ignore the landscape users, and unilateral in order to complete their design. Designers must pay attention to the visual, auditory, and olfactory feelings of building users, while also considering whether the safety of design materials meets national standards. [3]In order to design a truly people-oriented campus landscape, a comprehensive consideration of the entire ecosystem of campus landscape design should be involved. For example, when we design a stadium, we must take into account the characteristics of human movement. Meanwhile, the interior style and tone of stadium needs to make students feel comfortable. At the same time, when choosing decorative materials, try to use materials with good sound insulation to ensure that the noise control in the room is at a reasonable level. We must also take into account the facts that the decoration materials must not contain toxic and harmful substances in order to prevent damage to students' bodies. In this way, it also conveys the concept of honesty and reliability and the responsibility of society to students.

\section{B. The spirit of the place carrying memories}

Many colleges and universities are building new campuses on a large scale today. The places full of situations and memories in the old campus are gradually disappearing while the memory in the new campus site has not yet formed. This situation can lead users to lose their sense of belonging and identity to the environment. Norwegian urban architect Christian Norberg-Schulz believes that there are no substitutes for the place elements and the places, which are full of memories. They combine with the past and present, traditional ideas and present needs, and even forecast the future development.

Therefore, designers should start not only from the user's behavior activities, but also from the user's sensory experience and cultural spiritual feelings. Comprehensive consideration of the entire campus landscape design to protect the campus's "context", in this way, we can design a truly people-oriented campus landscape. For example, Stanford University's distinctive "Main Square" is the symbol and carrier of the campus spirit. Every year the opening ceremony and graduation ceremony of school held in this courtyard and the facade of the church constitutes to the solemn beautiful curtain and background. The first President of Jordan had said in his opening inscription, Long corridors and solemn columns will also be a part of student education, and every stone in the Main Square courtyard will teach people decency and honesty. [1] 


\section{The development and extension of regional spirit}

Campus landscape design not only reflects the ideology of the designer, but also reflects the aesthetic characteristics of the user. With the increasing trend of world economic integration, cultural exchanges between countries all over the world become more frequent. Against this background, many urban dwellers prefer the simplicity of European and American design style; Of course, there is no right or wrong for this kind of hobby, but if a person lives in such an environment for a long time, it is bound to affect his outlook on life and values. The regional spirit is the cultural background of the school landscape space and the comprehensive embodiment of the cultural characteristics and local customs of the school. Gradually forget their national culture and spiritual pursuit; it is definitely not the genius loci that University hopes to carry. Therefore, when designing the campus landscape, we must consider the local ethnic characteristics so that it can ensure the inheritance of national culture. Respect the local natural environment can maximize to protect the campus ecology, which is also the concept of getting college students to handle the relationship between man and nature concept.

\section{Considering the purpose of the place when designing}

Besides the beauty and characteristics, landscape design should also consider their uses. For example, when we design the environment of a shopping mall, the design of lights and shadows must be well because the light is decisive for the display of goods and the shopping mall is the place selling its main body, commodities. As a place where college students study and live, we need to consider the influence of color, material and light on people's spirit when planning and designing the campus. In addition, as for each university's specific requirements, we also have to listen carefully and adopt, such as the characteristics of the college students, preferences, learning characteristics, traditional habits etc. All the related factors need to communicate with university seriously and take into account in the process of design to provide a better-personalized landscape design for each university.

\section{E. The harmony of campus landscape with old and new buildings}

Because the choice of economical and reasonable building materials has a direct impact on the embodiment of landscape design ideas, designers must choose materials that conform to the design style. The first is to find the most suitable materials from the design concept and the actual situation of the university campus. It can not only harmonize the design style of the old and new buildings on campus, but also conform to the cost-effective of school to ensure the quality and effect of the design. Second, in the proposition guaranteeing quality and price, choose some new material, such not only can add design innovative, also embodies the spirit of university innovation. As Christian Norberg-Schulz said, "The change of place is inevitable, and the way to respond is to reinterpret creatively."[2]

\section{METHODS OF LANDSCAPE DESIGN}

\section{A. Function and material selection}

The main function of building decoration is to protect the main structure to improve the service life of buildings; enhance the use of buildings to bring people a comfortable feeling; enhance the aesthetic experience of buildings to beautify the environment. Therefore, a complete scene design must be from the inside to outside, from all angles and all angles.

The purpose of exterior decoration of the building is mainly to ensure the stability of the wall and beautify the facade. Therefore, when we choose the outside decorative materials, we must consider the function, strength level, location, and overall style of the building. [5]For some building with vast area and high grade, such as library, activity hall, etc., it is suitable to choose high-grade block decorative material, such as granite, marble, etc. For some living building, it is suitable to choose ceramic or cement mortar plastering architectural coatings and so on. For some teaching buildings, it is more suitable to use ceramic veneer bricks and the lower part with rough processing of natural granite plates can highlight the strong, stable, and textured effects. The purpose of the interior decoration of the building is to be clean and comfortable. With the rapid development of Chinese social economy, people are increasingly demand the quality of lift, so architectural interior decoration design needs to be from the overall indoor space effect to carry out the artistic conception to achieve the unity of function and artistic effect. Under normal circumstances, the interior decoration of the university pursues simplicity, brightness, and generosity and the choice of materials must be economical and durable. Do not blindly pursue quality, which will make the decoration too luxurious. Therefore, the general teaching places usually can choose colorful interior wall painting materials, a variety of ceramic decorative materials and rich patterns wallpaper, etc. Meanwhile, we can also choose artificial decorative panels, thin wood stickers and so on.

\section{B. The main points of the control}

\section{1) Elements for Outdoor Scenery Design}

The outdoor landscape design of the building needs to refer to the surrounding environment of the building and be consistent with the style of other buildings.

a) Color Requirements. The relationship between exterior decoration and the space-time environment color of the building is an issue that cannot ignore. For example, the color of the front door decoration must be consistent with the style of the entire building. When we design the color of the front door, we must adapt to the original building design style, so that it will not appear to be particularly abrupt, destroyed the space-time environment of the building.

b) The design of the whole. The exterior decoration design needs to have an overall idea from the artistic conception of the architectural environment, that is, it needs to make conceptual considerations on the atmosphere, mood, and characteristics of the architectural environment, and then express its own feelings in the form of language. 
c) Design should be contemporary and reflect functionality. The style of the decorative design allows people to recognize the type and nature of the building at a glance.

\section{2) Elements of interior scene design}

a) Consistency between design and requirements. The interior decoration design of the building needs to be consistent with the specific needs of the building. The specific plans for the interior decoration design of buildings with different properties also should be different. For example, interior decoration for teaching purposes requires simplicity, nature and the color of the classroom, as well as the texture of the walls and floors, should meet the requirements of quiet, neat and concise. The interior decoration design of the hotel pays more attention to the rich colors and wider space in order to reflect the magnificent effect of the hotel.

b) Reasonable planning and adjustment. When designing the interior decoration, it is necessary to make reasonable planning and adjustment to the established space in the room so that the space can be more hierarchical and meet the user's viewing and using needs.

Usually, for the treatment of interior space, we need to grasp the relations among top, wall and ground. For these three parts, we can through the indoor color-matching, pattern, line processing, lighting, lamp modeling and so on, so that the indoor space become more rich, more remarkable level.

For example, the top of the library hall is mainly located in the upper part of the entire indoor space. This is a very attractive area and the perspective sex is very strong. Via the rich sense of rhythm, elegant concave and convex graphics, appropriate location with a unique shape of lamps and lanterns in the right position, it can create a rich change, novel and beautiful pattern so that when people looking up, they can produce a sense of space and can also guide their vision.

Moreover, the library's ground has less impact on people than the top, but the design of this space cannot ignore. In reality, when designing the layout of the ground and counter, it can be relatively flexible, but also needs to meet people's habit of borrowing books. When we design the ground, we can adjust the continuity and rhythm of the patterns to meet the aesthetic standards of teachers and students. The impact of walls on people is the greatest, so we need to consider the design of doors, windows, vents, lamps, etc. to achieve a good natural lighting effect.

c) Texture and color of decorative materials. The interior decoration design, like the exterior decoration design, needs to consider the texture and color of the decorative material. For example, a rough surface with a rough texture can make people feel thick and open-minded, while fine materials make people feel dexterous and refined. Therefore, we must choose materials according to the actual situation of the room, in order to give people the enjoyment of the beauty.

\section{THE TREND OF THE DESIGN}

\section{A. Ecological trends in design}

Campus planning and construction has always paid great attention to the planning of the natural environment, protecting and utilizing the original natural factors of the landscape. Based on this reasonable planning, it fully displays the characteristics of the landscape brought by the natural factors, which can be very good in the campus to form an ecosystem [1]. In the campus planning and design, these original ecological areas and ecosystems will also become characteristic landscapes of the campus. For example, the design of Wuhan University's old dormitory and cherry blossom street make full use of the original natural conditions, introducing the mountain landscape and characteristic flowers into the campus, and become the important landscape node of Wuhan University. Secondly, ecological energy-saving buildings and the protection and utilization of natural energy are also important trends in eco-design.

\section{B. The trend of internal communication and opening to the outside world}

Students need to communicate within the campus and creating public open space and communication space for students is an expression of openness within the campus. This kind of space not only satisfies the exchange of students 'knowledge, but also satisfies the exchange of students' psychological feelings and creativity.

In the 21st century, the campus is no longer a closed ivory tower, which changed from introverted to extroverted and continues for a period. Modern information technology makes the sharing of knowledge technology and resources in universities become a new type of campus sharing, which makes the society knows the rich cultural atmosphere in the University. Moreover, this will exert a subtle influence on the cultural quality of cities and countries. [4]

\section{More distinctive trend}

University campus culture is the projection of social culture on campus. Each university has different historical background, structure, and cultivation goals. The history of a university is the most valuable asset and all the landscape, architecture and plants that carry such information should be protected and applied.

China is a vast country with rich landform, climate, biological species and even cultural customs [6].The campus landscape with these environmental features is unique.

\section{SUMMARY}

Campus is a place with multiple meanings, like historical memory, philosophical thinking, regional spirit and so on, which is not only determined by the objective material, but also because of the spirit which has been deposited for many years and has been continuing. With the rapid development of social economy and the increasing improvement of people's living standards, campus landscape design focused more on humanization, artistic, and characteristic development. It is necessary to define the position of the landscape design of the campus landscape, according which designer can determine the design style, building materials and color range and finally forms the design that the campus teachers and students can produce a sense of identity and resonance. Meanwhile the design also can have a good impact on students' world outlook and outlook on life. Genius loci on campus are another form of 
education for students, which conveys the spirit and quality that the school hopes the students have. Therefore, when we do the landscape design, we should not only simply integrate the concept of the times and improve the design method, but also think about how to constantly update the campus symbols and landscape image so that the genius loci of the Chinese campus can be recognized and sustainably developed in the continuous construction and go on.

\section{REFERENCES}

[1] Bai Han. Preliminary research university campus landscape [D]. Beijing forestry university, master's thesis, PP.1-2, June 2004.(In Chinese)

[2] (Norway) Christian. Norberg. Schulz; ShizhiMing translate. Genius Loci, Towards a Phenomenology of Architect [M]. Hubei: Huazhong University of Science and Technology Press, 2010.(In Chinese)

[3] Liang Hui Fen. Preliminary Analysis of Architectural Decoration and Architectural Culture[J]. Knowledge Economy, PP. 104, 2011(08).(In Chinese)

[4] Qu De Ying, Lv Chao Ya. Thinking about art and design of urban landscape[J]. Journal of Zhejiang University of Science and Technology, 2013(02). PP. 113-116.(In Chinese)

[5] Liu Xiang. The thinking of contemporary architecture interior design[J]. Art and design (theory), PP. 106-110, 2009(05).(In Chinese)

[6] Wang Yan Fei. University campus landscape and the place spirit [D].Nanjing forestry university, master's thesis, PP. 27-28, April 2009.(In Chinese)

[7] (USA) Richard. P. Bell. Campus landscape [M]. Beijing: China Water \& Power Press, April 2006.(In Chinese) 